\title{
(쇼
}

\section{If There Is No Trauma History, What's Happened?} Travma Öyküsü Yoksa Ne Oldu?

\author{
Serpil Yaylacı ${ }^{1}$, Mustafa Serinken² \\ 'Department of Emergency Medicine, Acıbadem University Faculty of Medicine, İstanbul, Turkey \\ ${ }^{2}$ Department of Emergency Medicine, Pamukkale University Faculty of Medicine, Denizli, Turkey
}

\section{ABSTRACT}

Introduction: Shaken baby syndrome (SBS) is probably an underestimated diagnosis. It is the leading cause of death from child abuse. Crying is thought to contribute to the act of shaking.

Case Report: A4-month-old girl presented to the emergency room with convulsions. She was unconscious with dilated pupils. In the detailed physical examination, she did not have any head or body trauma signs. The eye fundus examination showed extended retinal hemorrhagic areas. Her brain computerized tomography examination revealed a subdural hematoma at the posterior fossa near the posterior cerebellum at the level of the cisterna magna. The girl was admitted to the extensive care unit, where she died after 5 days. Her mother confessed that she had shaken the baby.

Conclusion: Shaken baby syndrome should be kept in mind with a baby with no trauma history and no trauma signs in the physical examination. An inconsistent history must alert for emergency physicians.

Keywords: Shaken baby syndrome, head, trauma, subdural hematoma

Received: 11.09.2014 Accepted: 30.09.2014

\section{ÖZET}

Giriş: Sarsılmış bebek sendromu (SBS) genellikle gözardı edilen bir tanıdır. Oysa çocuk istismarına bağlı ölümlerin önde gelen nedenlerindendir. Bebeğin aşıı derecede ağlamasının, bakıcıda sarsma isteğine yol açtığı düşünülmektedir.

Olgu Sunumu: Dört aylık kız bebek, nöbet geçirme öyküsü ile annesi tarafından acil servise getirildi. Fizik muayenede genel durum kötü, bilinç kapalı, solunum yüzeyel, pupiller dilate idi. Ayrıntılı fizik muayenede çocuğun kafa ve vücudunda herhangi bir travma belirtisi yoktu. Göz dibi bakısında sağda retinal yaygın hemorajik alanlar saptandı. Beyin bilgisayarlı tomografide posterior fossada cerebellum posterior komşuluğunda sisterna magna düzeyinde subdural hematom saptandı. Yoğun bakım ünitesine alınan bebek 5. günde eksitus oldu. Anne yasal soruşturma sırasında bebeği sarstığını itiraf etti.

Sonuç: Sarsılmış bebek sendromu, özellikle süt çocukluğu döneminde travmatik fizik muayene bulgusu veya travma öyküsü olmasa da akla getirilmelidir. Tutarsız hikaye uyarıcı olmalıdır.

Anahtar Kelimeler: Sarsılmış bebek sendromu, kafa, travma, subdural hematom

Geliş Tarihi: 11.09.2014 Kabul Tarihi: 30.09.2014

\section{Giriş}

Sarsılmış bebek sendromu (SBS), ilk olarak 1946 yılında tanımlanmıştır. Literatürde "sallanmış bebek sendromu", "hırpalanmış bebek sendromu" olarak da adlandırımaktadır. Çocuk istismarına bağlı gelişen bir kafa travması şeklidir. Olguların çoğu iki yaş altındadır ve bazı şiddetli olgularda hayatı tehdit edici sonuçlar görülebilir. Direkt travma olmadan, kraniyoservikal aksın rotasyonel akselerasyonuna bağlı olarak da gelişebilir. Retinal hemorajinin olması, kaza olmadığına işaret eder. Ülkemizde halen sağlık çalışanları arasında farkındalığı beklenenin altındadır $(1,2)$.

Sarsımış bebek sendromu olguları çocukluk çağı hastalıklarında sık görülen çeşitli semptomlar ile uyumlu şikâyetlerle acil servise başvurabilir. Bu yüzden ilk başvuruda SBS tanısını koymak kolay değildir (2). Bu yazıda annesi tarafından nöbet geçirme şikâyeti ile acil servise getirilen bir SBS olgusu sunulmuş ve bu olguların tanı süreci güncel literatür bilgileri ışığında tartışımıştır.

\section{Olgu Sunumu}

Dört aylık kız bebek, nöbet geçirme öyküsü ile annesi tarafından acil servise getirildi. Anneden alınan anamneze göre, önceden tamamen sağlıkı olan çocuk aniden kusmaya başlamış sonrasında nöbet geçirmişti. Travma öyküsü yoktu. Özgeçmişinde 


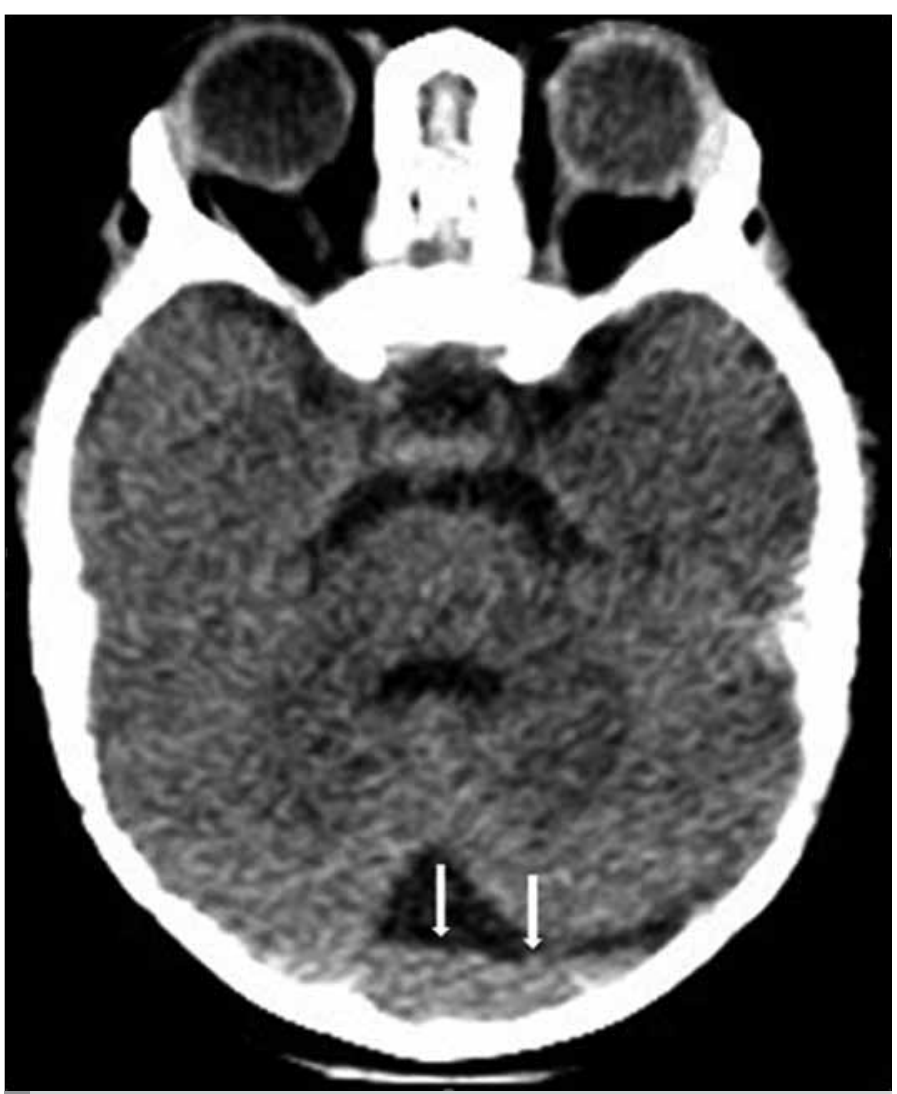

Resim 1. Aksiyal kranial BT görüntüsüne posterior fossada cerebellum posterior komşuluğunda sisterna magna düzeyinde yüksek dansiteli subdural kanama

herhangi bir özellik yoktu. Miadında normal vajinal yolla $2300 \mathrm{gr}$ olarak doğduğu, aşılarının tam olduğu, anne sütü aldığı ifade edildi. Soygeçmişinde; iki kardeşin küçüğü olduğu, anne-baba akrabalık olmadığı, ailede konvülsiyon öyküsü olmadığı öğrenildi.

Fizik muayenede genel durum kötü, bilinç kapalı, Nabız: 145/ dk.,tansiyon: 95/70 mmHg, solunum yüzeyel, pupiller dilate idi, ışık refleksi alınamadı. Ateşi 37 derece ölçüldü. GKS 3 olarak saptanan bebek, her hangi bir ajan kullanılmadan entübe edildi. Ayrıntılı fizik muayenede çocuğun kafa ve vücudunda herhangi bir travma belirtisi yoktu. Göz dibi bakısında sağda retinal yaygın hemorajik alanlar saptandı. Lateralize motor defisit yoktu. Derin tendon reflekslerinin alt ekstremitede hipoaktif olduğu belirlendi. Beyin bilgisayarlı tomografide (BT) posterior fossada cerebellum posterior komşuluğunda sisterna magna düzeyinde subdural hematom saptandı (Resim 1). Servikal, torakal ve batın BT'de patoloji saptanmadı. Koagülasyon profili normaldi. Tüm iskelet sistemi X-ray ile değerlendirildi. Kırık ya da kallus oluşumu izlenmedi.

Olası bir düşme ya da kaza öyküsü yeniden sorulduğunda, anne böyle bir şey olmadığını ifade etti. Yoğun bakım ünitesine alınan bebek 5. günde multiorgan yetmezliğinden eksitus oldu. Acil hekiminin şikayeti üzerine başlatılan yasal soruşturmada, anne bebeğini sarstığını itiraf etti.

\section{Tartışma}

İki yaş altı yaralanmaların yaklaşık yarısı istismara bağlı kafa travması nedenlidir. Bu çocukların \%30'u ölür, \%30'u iyileşir, \%40’ı ise ciddi nörolojik hasarlı kalır (3). Sarsılmış bebekler, sıklıkla solunum güçlüğü veya açıklanamayan nöbetle gelirler (4). Olgumuz da kusma ve ateşsiz nöbet öyküsüyle getirilmişti. Emmeme, genel durumda bozulma gibi genel yakınmaların SBS ile de ilişkili olabileceği akla getirilmelidir $(2,5)$. Olgumuzda da olduğu gibi saçlı derinin normal olması, hikayede travma öyküsü olmaması SBS'yi dışlatmaz. Öyküsü olmasa da SBS'de ciddi bir santral sinir sistemi travması vardır.

Sarsılmış bebek sendromunda sorun, subdural, epidural, interhemisferik ya da intraparankimal kanamaya ikincildir $(6,7)$. Bebeğin başı iki yaş altında vücut ağırlığının yaklaşık dörtte birine karşılık gelir. Bebeğin, eller arasında tutulup öne arkaya sallanması, ya da yüzeye (duvar, yatak vb.) fırlatılması sırasında anatomik olarak gelişimini tamamlamamış beyin, parankim ve vasküler yapıların yaralanması, yırtılmasına yol açabilir $(1,2)$.

Çocukluk yaş grubunda, ayırıcı tanı listesinde olası istismara yönelik risk değerlendirmesi yapmak ve dökümante etmek, acil serviste çalışan hekimlerin rutin hasta bakımı farkındalığı içinde yer almalıdır (8). Kraniyal görüntüleme ile beraber göz dibinin mutlaka uzman hekimler tarafından değerlendirilmesi gereklidir. X-ray ile iskelet taraması yapılması ve farklı yaşlarda ya da beklenmedik kırıklara rastlanıması tanıyı destekler $(2,9)$.

Düşünülmezse SBS, atlanabilecek bir tanıdır. Sanıldığının aksine sadece cani anne babalar, ya da bakıcılar değil, anlık öfke kontrol sorunu yaşayan ya da sadece sakinleştirmeye çalışırken bebeğin başını boynunu koruyamayan herkes bebeğe zarar verebilir. Bebeği beşikte ya da ayakta şiddetli şekilde sallama ile SBS arasındaki olası ilişki literatürde net olarak tanımlanmamıştır. Aile fertleri işe yaradığını düşünerek çocuğa uyguladıkları şiddeti giderek arttırabilir ve tekrarlayan sarsıntıların şiddeti zamanla artabilir. Özellikle ilk 3 ayda bebekler normal ama tolere edilmesi güç, tüketici bir ağlama paternine sahip olabilirler. Ağlama şiddeti 6-8. haftada pik yapar. Tahammülü zor, bu şiddetli ağlama paterni bebeğin sarsmaya maruz kalması için tetikleyici olabilir. Ebeveyn ya da bakıcının anlık şiddetli sarsması, öldürücü ya da sekel bırakacak ciddi yaralanmayla sonuçlanabilir (10). Anne baba ve bebek bakanların bu paterni öğrenmesi, SBS hakkında bilgilenmesi, sağlık profesyonellerinin bu konudaki eğitimi önemsemesi ve vermesi mortalitesimorbiditesi yüksek klinik antiteyi yönetmede önemli unsurlar olarak görünmektedir.

\section{Sonuç}

Özellikle süt çocukluğu döneminde travmatik fizik muayene bulgusu veya travma öyküsü olmasa da SBS akla getirilmelidir. Tutarsız hikaye uyarıcı olmalıdır. Olgular, daha çok aniden ortaya çıktığı söylenen klinik bulgular sebebiyle acil servise getirilirler. 
Informed Consent: Written informed consent was obtained from the patient's parents who participated in this case.

Peer-review: Externally peer-reviewed.

Author Contributions: Concept - S.Y.,M.S.; Design - S.Y.; Supervision - S.Y.; Materials - S.Y.; Data Collection and/or Processing - S.Y.; Analysis and/or Interpretation - S.Y.; Literature Review - S.Y.; Writer - S.Y.; Critical Review - M.S.

Conflict of Interest: The authors declared no conflict of interest.

Financial Disclosure: The authors declared that this study has received no financial support.

Hasta Onamı: Yazılı hasta onamı bu olguya katılan hastanın ailesinden alınmıştır.

Hakem değerlendirmesi: Dış bağımsız.

Yazar Katkıları: Fikir - S.Y, M.S.; Tasarım - S.Y.; Denetleme - S.Y.; Malzemeler - S.Y.; Veri toplanması ve/veya işlemesi - S.Y.; Analiz ve/veya yorum - S.Y.; Literatür taraması - S.Y.; YazıIı yazan - S.Y.; Eleştirel İnceleme - M.S.

Çıkar Çatışması: Yazarlar çıkar çatışması bildirmemişlerdir.

Finansal Destek: Yazarlar bu çalışma için finansal destek almadıklarını beyan etmişlerdir.

\section{References}

1. Balcı E, Gün I, Mutlu Şarlı \$, Akpınar F, Yağmur F, Öztürk A, Günay O Still an unknown topic: child abuse and "shaken baby syndrome". Ulus Travma Acil Cerrahi Derg. 2011; 17: 430-4. [CrossRef]

2. Piteau SJ, Ward MG, Barrowman NJ, Plint AC. Clinical and radiographic characteristics associated with abusive and nonabusive head trauma: a systematic review. Pediatrics. 2012; 130: 315-23. [CrossRef]

3. Laurent-Vannier A, Toure H, Vieux E, Brugel DG, Chevignard M. Longterm outcome of the shaken baby syndrome and medicolegal consequences: a case report. Ann Phys Rehabil Med. 2009; 52: 436-47. [CrossRef]

4. Yağmur F, Asil H, Per H, Coşkun A, Aslan D. Sarsılmış Bebek Sendromu \& 3 Olgu Sunumu. Adli Tip Derg 2010; 24: 42-9.

5. Yağmur F, Asil H, Canpolat M, Per H, Coşkun A. Kısa Mesafeli Düşme ve Sarsılmış Bebek Sendromu. Türkiye Klinikleri J Med Sci 2010; 30: 766-71. [CrossRef]

6. Karbeyaz K, Şahin S, Akkaya H, Balcı Y, Gündüz T. Sarsılmış Bebek Sendromu (Shaken Baby) Sonucu Ölüm; Olgu Sunumu. Adli Tıp Derg. 2012; 26: 134-40. [CrossRef]

7. Yalçın SS. Abusive head trauma: the place in scientific papers. Çocuk Sağlığı ve Hastalıkları Dergisi 2011; 54: 227-30.

8. Anderst JD. Assessment of factors resulting in abuse evaluations in young children with minor head trauma. Child Abuse Negl. 2008; 32 405-13. [CrossRef]

9. MoradY, Kim YM, Mian M, Huyer D, Capra L, Levin AV. Nonophthalmologist accuracy in diagnosing retinal hemorrhages in the shaken baby syndrome. J Pediatr. 2003; 142: 431-4. [CrossRef]

10. Barr RG, Trent RB, Cross J, Age-related incidence curve of hospitalized Shaken Baby Syndrome cases: Convergent evidence for crying as a trigger to shaking. Child Abuse \& Neglect 2006; 30: 7-16. [CrossRef] 